\title{
Modifications in plasma membrane lipid composition and morphological features of AH-130 hepatoma cells by polyenylphosphatidylcholine in vivo treatment
}

\author{
VINCENZO CINOSI $^{1}$, ROBERTO ANTONINI $^{1}$, PASQUALINA CRATERI ${ }^{2}$ and GIUSEPPE ARANCIA ${ }^{2}$
}

\author{
${ }^{1}$ Department of Clinical and Medical Therapy, University of Rome 'La Sapienza', Viale del Policlinico 155; \\ ${ }^{2}$ Department of Technology and Health, Italian National Institute of Health, Viale Regina Elena 299, 00161 Rome, Italy
}

Received December 9, 2010; Accepted January 10, 2011

DOI: $10.3892 /$ or.2011.1272

\begin{abstract}
The plasma membrane lipid composition in AH-130 hepatoma cells was found to change remarkably after polyenylphosphatidylcholine (PPC) treatment. Plasma membranes from cells grown in rats treated for 7 days i.v. with $20 \mathrm{mg} / \mathrm{kg} /$ day PPC, when compared to those of control cells, did not show significantly different amounts of cholesterol or phospholipids relative to protein content, but, surprisingly, the individual phospholipid distribution inside the two membrane leaflets changed dramatically. Phosphatidylcholine (PC), the major phospholipid in the external membrane leaflet, increased $~ 47 \%$ $(p<0.001)$. By contrast, phosphatidylethanolamine $(\mathrm{PE})$, the most important component of the inner leaflet, decreased nearly $37 \%$ ( $<<0.001)$, while sphingomyelin $(\mathrm{SM})$ also decreased $\sim 17 \%,(\mathrm{p}=0.1)$. Tumor cells collected from control rats at the same time interval and observed by scanning electron microscopy, exhibited a spherical shape with numerous and randomly distributed long microvilli, the same morphological and ultrastructural features displayed by the implanted cells. Conversely, tumor cells from PPC-treated rats no longer showed the roundish cell profile, and microvilli appeared shortened and enlarged, with the formation of surface blebs. Transmission electron microscopy observations confirmed the morphological and ultrastructural cell changes, mainly seen as loss of microvilli and intense cytoplasmic vacuolization. Taken together, these results indicate that the new phospholipid class distribution in the plasma membrane leaflets, modifying tumor cell viable structures, produced heavy cell damage and in many cases brought about complete cellular disintegration.
\end{abstract}

Correspondence to: Dr Vincenzo Cinosi, Department of Clinical and Medical Therapy, University of Rome 'La Sapienza', Viale del Policlinico 155, 00161 Rome, Italy

E-mail: vincenzo.cinosi@libero.it

Abbreviations: HDL, high density lipoprotein; PPC polyenylphosphatidylcholine

Key words: polyenylphosphatidylcholine treatment, HDL receptors, plasma membrane leaflets, Yoshida ascites hepatoma

\section{Introduction}

The composition of membrane lipids in tumor cells can be influenced considerably by the fatty acids added to the growth medium (1-5) or by changing the type of fat fed to the tumor-bearing animals (6-10). Biochemical modification of membrane fatty acids results in changes in physical properties such as membrane fluidity $(1,11)$ and drug transport $(3,8,12)$. These changes affect membrane dynamics and result in increase in cellular susceptibility to antineoplastic drugs (3) and enhanced susceptibility to lipid peroxidation $(4,13)$.

However, what occurs in cell membranes, as well-demonstrated, especially in plasma membrane $(6,8)$, is a substitution of phospholipid fatty acyl chains without any overall disturbance in the architecture of the membrane lipid bilayer. No changes occur in the membrane phospholipid or cholesterol content.

Since fatty acid replacements do not appear to consistently influence tumor growth, considering, in agreement with Spector and Burns (14), that other membrane lipid component modifications, such as phospholipid head groups, might affect tumor cell viability, we attempted to modify phospholipid distribution in tumor cell membranes. Even though from a practical standpoint, according to the above-mentioned authors (14), it could be difficult to bring about phospholipid changes by in vivo treatment, we decided to administer a particularly polyunsaturated phospholipid to the hepatoma tumor-bearing animals.

Among various tumor types, hepatomas display a dramatic decrease in phospholipid content in cell membranes when compared to normal counterparts, and phosphatidylcholine proportion is especially reduced (15-17). In addition, the content of polyunsaturated fatty acids in phospholipids is lower in hepatoma cell membranes than in those of hepatocytes $(16,17)$. Because phosphatidylcholine represents the major phospholipid class of membrane phospholipid components, we chose to administer a highly polyunsaturated phosphatidylcholine [very rich in linoleic acid (18:2)] to Yoshida ascites hepatoma-bearing rats, with the aim of causing lipid modifications in tumor cell membranes as far as possible. Results of the present study demonstrate that polyenylphosphatidylcholine (PPC) administration has the ability to restore to a large extent the membrane phospholipid patrimony in tumor cells, producing 
significant rearrangements of the lipid plasma membrane distribution and dramatic tumor cell damage.

\section{Materials and methods}

Animals and treatments. The animal experimentation was carried out at the Regina Elena Cancer Institute in Rome, in accordance with the Italian laws regulating the in vivo investigations approved by the Italian Ministry of Health. Male Wistar rats, weighing 180-200 g, were used as a host for Yoshida ascites AH-130 (4) hepatoma transplants. This hepatoma was maintained by transplantation of tumor cells in rats through i.p. serial passages of $1 \mathrm{ml}$ of tumor suspension $\left(2-3 \times 10^{7}\right.$ cells) carried out at 7 day intervals.

For PPC treatment, Lipostabil $\mathrm{N}$ i.v. solution was used (Nattermann \& Cie GmbH, Cologne, Germany). The qualitative and quantitative composition of $5 \mathrm{ml}$ aqueous injectable preparation was: $250 \mathrm{mg}$ phosphatidylcholine (active ingredient), $122 \mathrm{mg}$ deoxycholic acid, $45 \mathrm{mg}$ benzyl alcohol, $17.5 \mathrm{mg}$ sodium chloride and $0.5 \mathrm{mg}$ DL- $\alpha$-tocopherol (excipients).

Two groups of animals, each of them comprising 20 rats, after i.p. injection of $2 \times 10^{6}$ hepatoma cells were studied. The animals were fed a standard diet and water ad libitum. One of the two groups was treated with a dose of Lipostabil corresponding to $20 \mathrm{mg} / \mathrm{kg} /$ day of polyenylphosphatidylcholine. The second group was treated with only the excipient components of Lipostabil, at the same concentrations present in the dose administered to the other group, and then considered as control. The administration was started the day after tumor implantation. On days 7 and 10 the hepatoma tumor cells were collected from the peritoneal cavity of both treated and control rats, washed with phosphate-buffered solution (PBS) and then analysed.

Plasma membrane isolation. Plasma membranes were isolated essentially according to the procedures of Koizumi et al (18): it is of interest to note that following such procedures, it was possible to obtain a complete removal of contaminating erythrocytes from the collected tumor cells. Moreover, plasma membrane fraction was obtained as a well distinct band at the interface between 20 and $42 \%$ sucrose layers. In addition, mitochondria, cell debris and undisrupted cells were easily recovered, whereas nuclei were sedimented at the bottom of the tube.

All membrane isolation procedures were carried out at $4^{\circ} \mathrm{C}$. ATPase activity of plasma membrane was determined by the method of Nakao et al (19). The $\mathrm{Na}^{+}-\mathrm{K}^{+}$-ATPase activity was obtained from the difference of total ATPase and $\mathrm{Mg}^{2+}$ -ATPase activities. Assay of 5'-nucleotidase activity was performed according to the method of Gerlach and Hiby (20).

Electron microscopy. At the end of treatment, Yoshida cells collected from control and PPC-treated rats were immediately processed for transmission (TEM) and scanning (SEM) electron microscopy and then examined with a Philips 208S transmission electron microscope (FEI Company, Eindhoven, The Netherlands), or Cambridge stereoscan 360 scanning microscope (Cambridge Instruments Ltd., Cambridge, UK), respectively.

For TEM, collected cells were washed and then fixed with $2.5 \%$ glutaraldehyde in $0.2 \mathrm{M}$ cacodylate buffer, $\mathrm{pH} 7.2$, for $1 \mathrm{~h}$, postfixed with $1 \% \mathrm{OsO}_{4}$ in $0.2 \mathrm{M}$ cacodylate buffer, $\mathrm{pH} 7.2$, dehydrated with ascending concentrations of ethanol and embedded in epoxy resin (Agar 100, AGAR Scientific, Stansted, UK). Ultrathin sections obtained with an LKB Ultratome Nova ultramicrotome (LKB, Bromma, Sweden) were stained with uranyl acetate and lead citrate.

For freeze-fracture (FF) analysis, after fixation with $2.5 \%$ glutaraldehyde tumor cells were incubated with $25 \%$ glycerol in PBS and kept for $30 \mathrm{~min}$ at room temperature. The suspensions were then centrifuged at $1000 \mathrm{rpm}$ for $10 \mathrm{~min}$, put on carriers, and quickly frozen in freon 22 which was partially solidified by cooling with liquid nitrogen. The mounted carriers were then transferred into a Bal-Tec BAF 060 freezeetch unit (Bal-Tec Inc, Balzers, Liechtenstein), cleaved at $-100^{\circ} \mathrm{C}$ at a pressure of $2-4 \times 10^{-7} \mathrm{mbar}$, shadowed with $2.5 \mathrm{~nm}$ of Pt-C (at an angle of $45^{\circ}$ ) and replicated with $20 \mathrm{~nm}$ of C. Cells were digested overnight by chlorox and replicas were mounted on naked 300 mesh grids.

For SEM, the cells were allowed to attach for $15 \mathrm{~min}$ to glass coverslips pretreated with $0.01 \%$ aqueous poly-L-lysine hydrobromide, then fixed with $2.5 \%$ glutaraldehyde in $0.1 \mathrm{M}$ cacodylate buffer, $\mathrm{pH} 7.2$, added with $2 \%$ sucrose for $20 \mathrm{~min}$. After postfixation with $1 \% \mathrm{OsO}_{4}$ in $0.2 \mathrm{M}$ cacodylate buffer, $\mathrm{pH} 7.2$, for $30 \mathrm{~min}$, cells were dehydrated through graded ethanol concentrations, critical point-dried in $\mathrm{CO}_{2}$ (CPD 020 Balzers device) and gold-coated by sputtering (SCD 040 Balzer device).

Chemical and statistical analyses. Plasma membrane protein content was determined by the procedure of Lowry et al (21) using bovine serum albumin as a standard. Lipids were extracted from the purified plasma membranes with $\mathrm{CHCl3}: \mathrm{CH} 3 \mathrm{OH}$ $(2: 1, \mathrm{v} / \mathrm{v})(22)$. An aliquote of the lipid extract was used for cholesterol determination by gas-liquid chromatography as described by Vieu et al (23). Additional aliquots were used to measure phospholipids according to their phosphorous content (24) following lipid extraction.

Phospholipid classes were separated by two-dimentional TLC as previously described by Fourcade et al (25) using for the first dimension a mixture of chloroform, methanol and ammonia (65/25/5), and for the second dimension a mixture of chloroform, methanol, acetic acid and water (45/20/6/1) as solvents. Results are expressed as the means \pm SD. Statistical comparisons were performed using the Student's t-test, for unpaired samples.

\section{Results}

Yoshida tumor cells grown in PPC-treated rats underwent significant modifications in their plasma membrane composition. The enzyme-specific activities of the purified plasma membranes $\left(\mathrm{Na}^{+}-\mathrm{K}^{+}\right.$-ATPase, $\mathrm{Mg}^{2+}$-ATPase and 5'-nucleotidase) were enriched 10-, 8- and 6-fold, respectively, as compared to the crude homogenate. Electron microscopy of the plasma membrane fraction revealed a predominance of membrane structures of various sizes, and confirmed the subcellular fraction identification (data not shown).

Plasma membranes of the cells from treated animals, collected after day 7 of PPC administration, showed a remarkable difference in the individual phospholipid distribution as 
Table I. Plasma membrane lipid content. ${ }^{a}$

\begin{tabular}{|c|c|c|c|}
\hline Lipid & Control cells & \multicolumn{2}{|c|}{ PPC-treated cells } \\
\hline \multicolumn{4}{|l|}{ Lipid composition } \\
\hline Cholesterol: protein $(\mu \mathrm{g} / \mathrm{mg})$ & $137.3 \pm 14.1$ & $134.2 \pm 13.4$ & (N.S.) \\
\hline Cholesterol: phospholipid (mol/mol) & $00.39 \pm 0.01$ & $00.40 \pm 0.03$ & (N.S.) \\
\hline Phospholipid: protein $(\mu \mathrm{g} / \mathrm{mg})$ & $692.5 \pm 61.3$ & $657.8 \pm 23.1$ & (N.S.) \\
\hline \multicolumn{4}{|l|}{ Major phospholipids (\%) } \\
\hline Phosphatidylcholine & $32.8 \pm 3.8$ & $48.3 \pm 5.7$ & $(* *)$ \\
\hline Phosphatidylethanolamine & $27.3 \pm 2.0$ & $17.2 \pm 2.4$ & $(* *)$ \\
\hline Sphingomyelin & $22.1 \pm 1.5$ & $18.4 \pm 2.1$ & $(*)$ \\
\hline Serine and inositol phosphoglycerides & $15.3 \pm 2.2$ & $14.1 \pm 3.0$ & (N.S.) \\
\hline Lysophosphatidylcholine & $01.4 \pm 0.4$ & $01.6 \pm 0.2$ & (N.S.) \\
\hline
\end{tabular}

aPurified plasma membrane fractions were extracted with $\mathrm{CHCl} 3: \mathrm{CH} 3 \mathrm{OH}(2: 1)$. Cholesterol, protein and phospholipids were measured as described in Materials and methods. These values are expressed as the mean \pm SD determined from 5 separate membrane preparations. The differences of the values between the control-treated cell membranes are not statistically significant (N.S., p $>0.05$ ). The major phospholipids were separated by two-dimensional thin-layer chromatography. The segments of the silica gel corresponding to authentic standards were scraped and extracted with $\mathrm{CHCl} 3: \mathrm{CH} 3 \mathrm{OH}(1: 1)$, and the lipid phosphorus content was determined $\left({ }^{* *} \mathrm{p}<0.001 ;{ }^{*} \mathrm{p}=0.1\right)$.

compared to those of the control cells collected at the same time interval. Control cell plasma membranes from rats treated for 7 days with Lipostabil additives showed the same individual phospholipid distribution as the implanted cells. The two membrane preparations, from treated and control cells, did not contain statistically significant differences in the amounts of cholesterol and phospholipid, relative to protein content. Moreover, the molar ratio of cholesterol to phospholipid was similar in both preparations (Table I).

In spite of the fact that total phospholipid content in the plasma membrane of treated cells did not show changes, the distribution of the different phospholipid classes was dramatically changed. Phosphatidylcholine, the major phospholipid class located in the external leaflet of the membrane, was considerably increased up to $\sim 47 \%$ (Table I); sphingomyelin level, on the contrary, was decreased by $\sim 17 \%$. The behaviour of phosphatidylethanolamine appeared to be particularly interesting: such phospholipid, which in many tumor types displays a significant increase, in the hepatoma cells under PPC treatment showed a very surprising decrease. The observed decrease was nearly 37\% (Table I). Serine and inositol phosphoglycerides did not show appreciable differences, when measured in both membrane preparations. In addition, there was no difference in the percentage composition of lysophosphatidylcholine in the membranes from each of the cell samples examined.

In order to investigate the possible morphological and ultrastructural changes induced by the modifications of the plasma membrane lipid composition, observations by both scanning (SEM) and transmission (TEM) electron microscopy were carried out on control and PPC-treated hepatoma cells. When collected from the peritoneal cavity of control rats, treated for 7 days with Lipostabil excipients, Yoshida cells showed the same morphological and ultrastructural features as the implanted cells. Observed by SEM, they exhibited the typical morphology characterized by a spherical shape, with a diameter ranging from 10 to $15 \mu \mathrm{m}$, and the surface covered with numerous and randomly distributed long microvilli (Fig. 1a and b).

On the contrary, tumor cells grown in PPC-treated animals and collected at the same time interval, showed very evident morphological alterations (Fig. 1c). Most of them appeared swollen, the cell profile was no longer roundish and the surface microvilli had become shortened and enlarged. Moreover, some of these cells displayed important cell damage signs, mainly consisting in the formation of numerous and large surface blebs (Fig. 1d). In addition, many tumor cells appeared to be lethally damaged, producing cellular debris easily detectable in the background (arrows in Fig. 1c).

TEM observations confirmed a remarkable effect of the PPC treatment on the ultrastructural features of Yoshida cells. Control cells (Fig. 2a) showed well preserved morphology: the intracellular organelles appeared to be intact and numerous long microvilli were present on the cell periphery, confirming SEM observations. After 7 days of PPC administration, most of the tumor cells still maintained quite a good morphological preservation even though the plasma membrane especially showed evident changes with the appearance of numerous small surface blebs (Fig. 2b).

In rats treated for 10 days, the ascites hepatoma cells underwent very important morphological and ultrastructural changes (Fig. 2c) consisting in altered shape, loss of microvilli, intense cytoplasmic vacuolization and alterations of the cytoplasmic organelles. In particular, in numerous cells (Fig. 2d), most of the mitochondria showed condensed matrix with deranged and dilated cristae. Interestingly, animals under PPC treatment showed a longer time survival compared to control animals, even though such difference was not statistically significant (data not shown).

Furthermore, the observation of control and treated tumor cells, processed for TEM by the freeze-fracture method, allowed us to analyze the effects of PPC treatment on the plasma membrane molecular organization. In control cells, the 

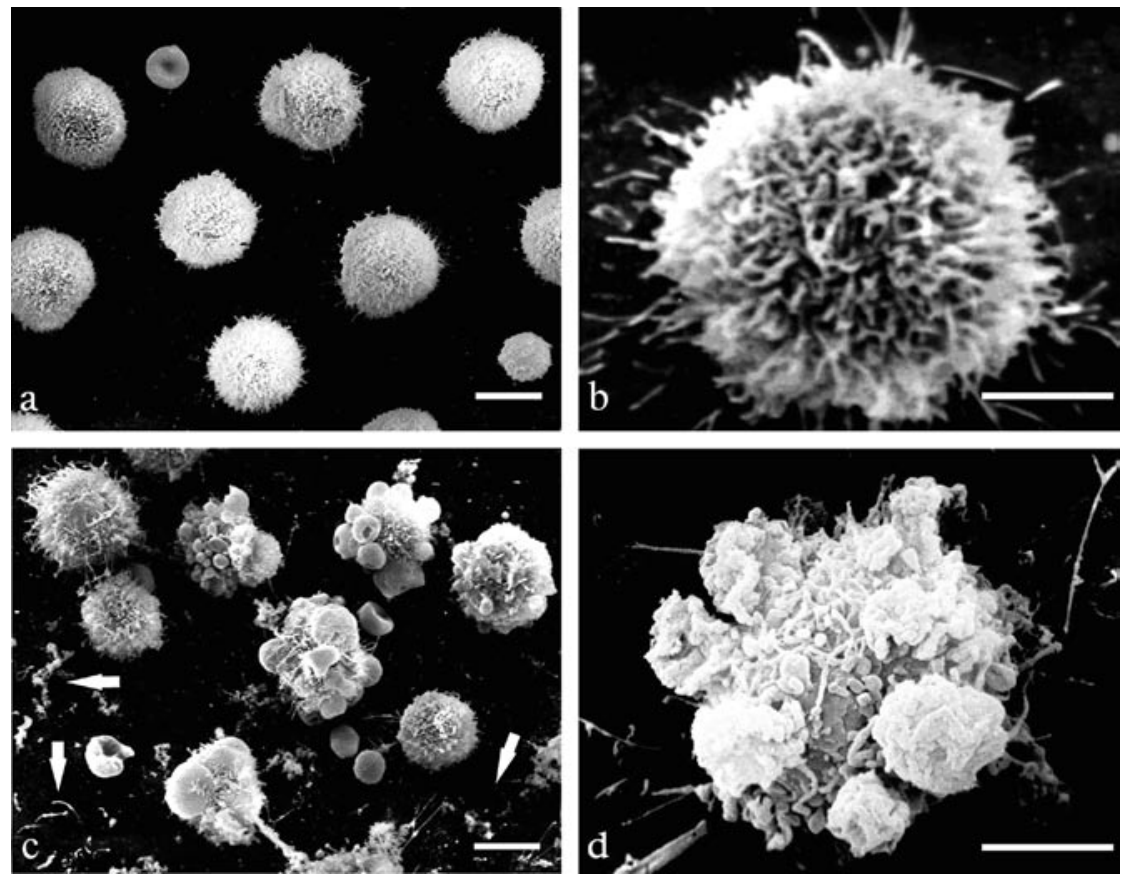

Figure 1. Yoshida cells collected from the peritoneal cavity of control and PPC-treated rats, observed by scanning electron microscopy (SEM). Control cells showed their typical morphology characterized by spherical shape with a diameter of 10-15 $\mu \mathrm{m}$ (a). At higher magnification, numerous long microvilli could be observed on the cell surface (b). PPC-treatment induced evident morphological alterations in Yoshida cells (c), mainly consisting in the formation of large surface blebs (d). Bars $=10(\mathrm{a}, \mathrm{c})$ and $5 \mu \mathrm{m}(\mathrm{b}, \mathrm{d})$.
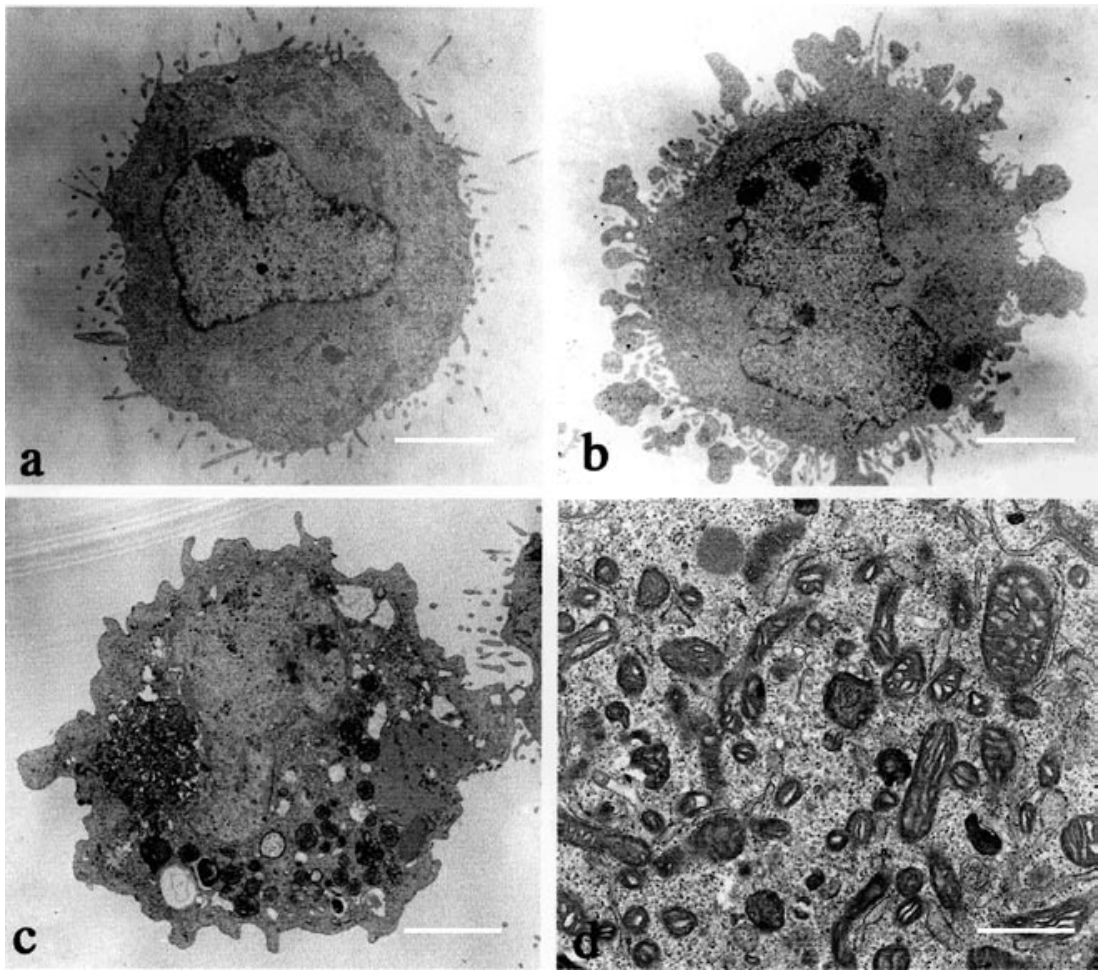

Figure 2. Yoshida cells collected from control and treated rats, observed by transmission electron microscopy (TEM). The observations at low magnification confirmed the morphological features revealed by SEM of both control (a) and treated (b) cells. After longer period of treatment, hepatoma cells underwent remarkable ultrastructural changes (c); in particular, the majority of mitochondria showed condensed matrix and dilated cristae (d). Bars $=5$ (a,b,c) and $1 \mu \mathrm{m}(\mathrm{d})$.

intramembrane particles appeared to be randomly distributed in both exoplasmic and protoplasmic fracture faces of the plasma membrane (Fig. 3a and b, respectively); often, numerous cross-fractured microvilli could be observed (Fig. 3b). 

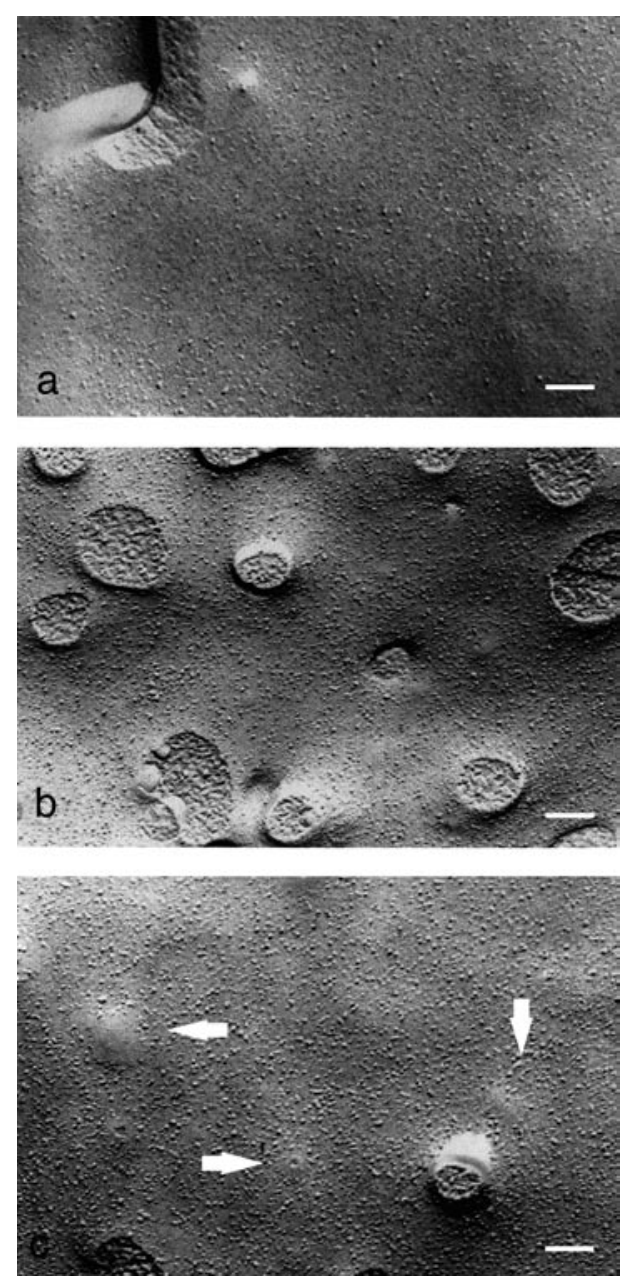

Figure 3. Freeze-fracture analysis of the effects of PPC-treatment on the plasma membrane ultrastructure. In control Yoshida cells, the protein intramembrane particles appeared to be randomly distributed on both exoplasmic (a) and protoplasmic (b) fracture faces of the plasma membrane. After PPC-treatment, numerous roundish smooth areas devoid of protein particles could be observed on the protoplasmic face (c). Bars $=0.1 \mu \mathrm{m}$.

By observing treated cells, no significant modification could be pointed out in the exoplasmic fracture face, whereas in the protoplasmic fracture face the number of cross fractured microvilli appeared to be strongly reduced (Fig. 3c).
Moreover, in the inner monolayer of the plasma membrane the protein particle distribution appeared to be modified with the presence of numerous roundish smooth areas (arrows in Fig. 3c). These lipid domains might be due to the new phospholipid arrangements brought about by PPC administration and probably represent significant modifications in the molecular composition and organization of the tumor cell plasma membranes.

Finally, in order to verify whether the administration of PPC to hepatoma-bearing rats might also induce alterations to normal cells, various tissues collected from treated and control animals were examined by TEM. Surprisingly, no significant effect was noted in any of the histotypes examined. Fig. 4 shows the comparison between a lymphocyte from the peripheral blood of a control animal (a), and the same cell type collected from a PPC-treated rat (b). The morphological aspect of control and treated lymphocytes appears to be perfectly comparable.

\section{Discussion}

In the present study important modifications of the plasma membrane lipid composition in AH-130 hepatoma cells were obtained. The major variation, after PPC treatment, was the remarkable augmentation of $\mathrm{PC}$ content in the tumor cell plasma membranes.

In hepatoma cells, as reported by several authors (15-17), phosphatidylcholine, which is located in the outer leaflet of the plasma membrane bilayer, showed a lower content compared to that of normal counterparts, whereas SM in the same membrane leaflet and PE, in the inner leaflet, appeared increased. Thus, it was surprising to observe that the PC increase (nearly 50\%) in the plasma membrane of treated cells, was not only able to produce a decrease of SM, but also a significant decrease of PE, which represents the most important component of the inner membrane leaflet. The new distribution of main phospholipid classes occurring inside the two membrane leaflets, producing a critical rearrangement of the membrane components, resulted in the deep architectural alterations of such structure and dramatic damage to the tumor cells.

It has been well documented (26) that intravenously injected PPC is incorporated into the HDL particles and around $80 \%$ of the injected dose after $1 \mathrm{~h}$ is still transported by the HDLs.
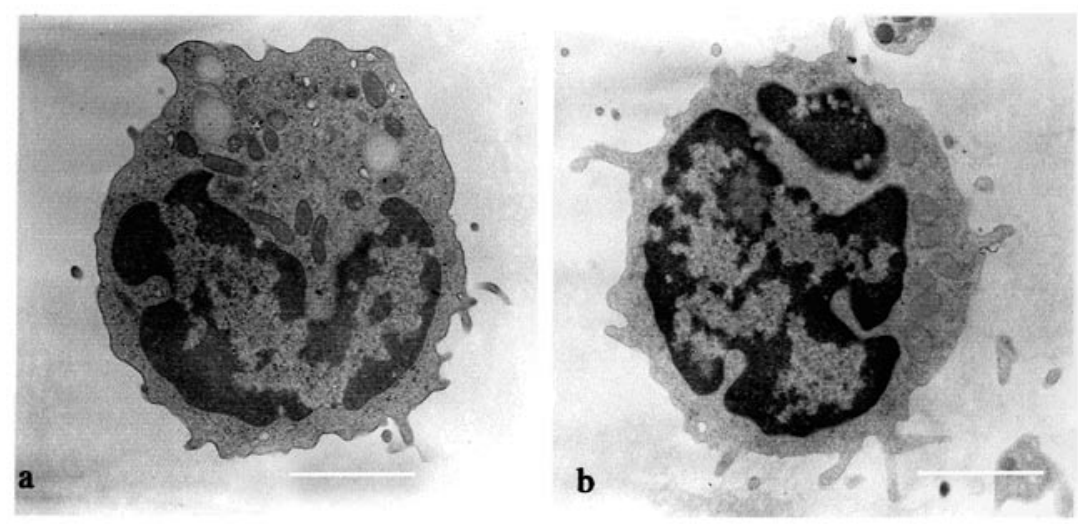

Figure 4. Peripheral blood mononuclear cells from control (a) and PPC-treated (b) hepatoma bearing rats, observed by TEM. No evident morphological and ultrastructural difference could be observed between control and treated cells. Bars $=5 \mu \mathrm{m}$. 
Indeed, it is well known that the various HDL particle subpopulations can continuously undergo modifications in their lipid core content and in the phospholipid surface components under the action of cholesterol ester transfer protein (CETP) $(27,28)$ and phospholipid transfer protein (PLTP) (29-32), respectively. However, in animals treated i.v. with PPC (26), the percentage portion of PPC in HDLs, after $3 \mathrm{~h}$, was still approximately $75 \%$ of the whole HDL PC fraction. Therefore, among the various mechanisms which could have determined the striking membrane phospholipid distribution in tumor cells, probably, the most important can be represented by the ability of the HDL plasma lipoproteins to transport i.v. administered PPC.

Studies performed on the interaction occurring between HDLs and cellular receptors, as reported by Barbaras et al (33) and Garcia et al (34), clearly demonstrated that HDL particles were internalized into hepatoma cells through an endocytosis pathway, before the transfer of particle components could occur. It is reasonable, therefore, to suggest that the injected PPC was easily transferred to tumor cells. The HDL particles, which have been shown to travel a long time with incorporated PPC (26), could very likely improve the lipid transport and favor the new phospholipid distribution in plasma membranes of tumor cells.

The morphological alterations observed in the tumor cell profile, mainly characterized by the cellular protrusions which became evidently shorter and enlarged during PPC treatment, and the lipid compositional rearrangement inside the two membrane leaflets displaying the presence of lipid domains in the inner leaflet, lead us to argue that these important structural changes were able to produce lethal conditions for the tumor cells.

Recent reports have demonstrated a central role of nonapoptotic blebbing concerning cell migration and cancer cell invasion (35), but, under our experimental conditions, the evident bleb formation seems to be due to the induction of apoptotic cell death, as well demonstrated by the ultrastructural alterations observed by TEM.

Moreover, the condensation of nuclear chromatin at the nuclear periphery, accompanied by blebbing of the cytoplasmic membranes and intense cytoplasmic vacuolization with the organelle degradation, suggest that different processes could be responsible for the deep alterations of tumor cells, resulting in the death of the cell.

Apoptosis, which is a caspase-dependent process, appears mainly characterized by nuclear condensation and fragmentation $(36,37)$, whereas autophagic cell death, a caspase-indipendent process (38-40), displays the accumulation of autophagic vacuoles accompanied by the degradation of cytoplasmic organelles, which precedes the destruction of nucleus. Apoptosis can begin with autophagy, and autophagy can end with apoptosis (40), thereby in treated cells such processes migth have contributed to determine lethal damage to the tumor cells. Both such processes may coincide within the same cells (41).

However, the remarkable increase of phosphatidylcholine in the plasma membrane producing a new equilibrium of the individual phospholipid distribution, probably by means of the activation or inhibition of some enzymes, such as aminophospholipid translocase (APTL) $(42,43)$, phospholipid scramblase (PLSCR) (44-46) and flippase (47), was able to bring about damage to the tumor cells and eventually cell death. It is evident that various biochemical processes could be involved, but it would seem that the increased availability of phosphatidylcholine offered by the HDL particles tended to lead the tumor cells back towards normality, favoring the re-integration of their plasma membrane phospholipid patrimony as far as possible similar to that of the normal counterparts, thus making these cells no longer able to perform their peculiar viable functions.

PPC administration did not seem to influence the morphological features of the plasma membrane in normal cells, or induce cellular alterations. Probably, even though it is difficult to provide one precise biochemical explanation, the HDL particles travelling with incorporated PPC were able to transfer, through the cell surface receptors, different amounts of phospholipids in accordance with the different needs of normal and cancer cells. The action of PPC, therefore, appeared to be mainly directed to tumor cells.

In addition, it is noteworthy to consider that in animals bearing ascites tumor, as demonstrated by Van Blitterswijk et al (48), the flux of lipoproteins from peripheral blood into the ascites compartment is limited. Thus, the HDLs during PPC treatment might more easily reach tumor cells inside the other anatomical locations.

In conclusion, the changes occurring in the plasma membrane of tumor cells, deeply modifying a viable cell structure, brought about, under the same conditions of whole organism heavy damage of these cells, thus making them less viable, and in many cases leading them to complete cellular disintegration. Since modifications of fatty acid composition in the plasma membrane of tumor cells, as well demonstrated by several authors $(2,3,8,12,49)$, have been shown to be able to increase the sensitivity of these cells to antineoplastic drug actions, we believe that it is reasonable to expect that structural alterations in the architecture of the plasma membranes could even more facilitate the action of such drugs against the cancer cells. Therefore, further studies are in progress in our laboratories to understand what biochemical mechanisms could be responsible for the damage occurring in cancer cells treated with PPC and find out whether and to what extent the associated action of different antineoplastic drugs will be able to cause cell death.

\section{Acknowledgements}

The authors are greatly indebted to Dr A. Molinari and Dr A. Calcabrini for their valuable assistance and Mr. L. Camilli for the skillful photographic work.

\section{References}

1. Guffy MM, Rosenberger JA, Jdo S and Burns CP: Effect of fatty acid alteration on hypertermic sensitivity in cultured L1210 murine leukemia cells. Cancer Res 42: 3625-3630, 1982.

2. Guffy MM, North JA and Burns CP: Effect of cellular fatty acid alteration on Adriamycin sensitivity in cultured L1210 murine leukemia cells. Cancer Res 44: 1863-1866, 1984.

3. Burns CP and North JA: Adriamycin transport and sensitivity in fatty acid modified leukemia cells. Biochim Biophys Acta 888: 10-17, 1986.

4. Canuto RA, Muzio G, Biocca ME and Dianzani MU: Lipid peroxidation in rat AH-130 hepatoma cells enriched in vitro with arachidonic acid. Cancer Res 51: 4603-4608, 1991. 
5. Wagner BA, Buetner GR and Burns CP: Membrane peroxidative damage enhancement by the ether lipid class of antineoplastic agents. Cancer Res 52: 6045-6051, 1992.

6. Awad AB and Spector AA: Modification of the fatty acid composition of Ehrlich ascites tumor cells plasma membranes. Biochim Biophys Acta 426: 723-731, 1976.

7. Kaduce TL, Awad AB, Fontenelle L J and Spector AA: Effect of fatty acid saturation on $\alpha$-aminoisobityric acid transport in Ehrlich ascites cells. J Biol Chem 252: 6624-6630, 1977.

8. Burns CP, Lattenegger DG, Dudley DT, Buetner GR and Spector AA: Effect of modification of plasma membrane fatty acid composition on fluidity and methotrexate transport in L1210 murine leukemia cells. Cancer Res 39: 1726-1732, 1979.

9. Eleghede JA, Elson CE, Qureshi A, Dennis WH and Yatvin MB: Increasing the thermo sensitivity of a mammary tumor (Ca755) through dietary modification. Eur J Cancer Clin Oncol 22: 607-615, 1986.

10. Jurkowski JJ and Cave WT Jr: Dietary effects of menhaden oil on the growth and membrane lipid composition of rat mammary tumors. J Natl Cancer Inst 74: 1145-1150, 1985.

11. Burns CP, Lambert BJ, Hangstad BN and Guffy MM: Influence of rate of heating on thermo-sensitivity of L1210 leukemia membrane lipids and M 70000 heat shock protein. Cancer Res 46: 1882-1887, 1986

12. Burns CP, Hangstad BN, Mossman CJ, North JA and Ingraham LM Membrane lipid alteration effect on cellular uptake of mitoxantone. Lipids 23: 393-397, 1988.

13. Burns CP and Wagner BA: Heightened susceptibility of fish oil polyunsaturated enriched neoplastic cells to ethane generation during lipid peroxidation. J Lipid Res 32: 79-87, 1991.

14. Spector AA and Burns CP: Biological and therapeutic potential of membrane lipid modification in tumors. Cancer Res 47 4529-4537, 1987

15. Wood R: Hepatoma host liver and normal rat liver phospholipids as affected by diet. Lipids 10: 736-745, 1975.

16. Wood R, Upreti GC and de Antueno RJ: A comparison of lipids from liver and hepatoma subcellular membranes. Lipids 21 292-300, 1986

17. Rethy A, Trevisani A, Manservigi R and Tomasi V: Isolation and characterization of the plasma membrane from Yoshida hepatoma cells. J Membrane Biol 20: 99-110, 1975.

18. Koizumi K, Shimizu S, Koizumi KT, et al: Rapid isolation and lipid characterization of plasma membranes from normal and malignant lymphoid cells of mouse. Biochim Biophys Acta 649: 393-403, 1981

19. Nakao K, Kurashina S and Nakao M: Adenosinetriphosphatase activity of erythrocyte membrane in hereditary spherocytosis Life Sci 6: 595-600, 1967.

20. Gerlach U and Hiby W: Methods of Enzymatic Analysis Bergmeyer HU (ed). Academic Press, New York, pp871-875, 1974.

21. Lowry OH, Rosenbrough NJ, Farr AL and Randall RJ: Protein measurement with the Folin phenol-reagent. J Biol Chem 193: 265-275, 1951

22. Folch J, Lees M and Sloane Stanley GH: A simple method for the isolation and purification of total lipids from animal tissues. J Biol Chem 226: 497-509, 1957.

23. Vieu C, Jaspard B, Barbaras R, et al: Identification and quantification of diacylglycerols in HDL on accessibility to lipase. J Lipid Res 37: 1153-1161, 1996.

24. Böttcher CJF, Van Gent CM and Pries C: A rapid sensitive submicrophosphorus determination. Anal Chim Acta 24: 203-204, 1961.

25. Fourcade O, Simon MF, Vlodé C, et al: Secretory phospholipase A2 generates the novel lipid mediator lysophosphatidic acid in membrane microvescicoles shed from activated cells. Cell 80 919-927, 1995

26. Zieremberg $\mathrm{O}$, Odenthal $\mathrm{J}$ and Betzing $\mathrm{H}$ : Incorporation of polyenephosphatidylcholine into serum lipoprotein after oral or intravenous administration. Atherosclerosis 34: 259-276, 1979.

27. Hennessy LK, Kunitake ST and Kane JP: Apolipoprotein A-I containing lipoproteins with or without apolipoprotein A-II as progenitors of pre-beta high density lipoprotein particles. Biochemistry 32: 5759-5765, 1993.

28. Liang HQ, Rye KA and Barter PJ: Dissociation of lipid-free apolipoprotein A-I from high density lipoproteins. J Lipid Res 35: 1187-1199, 1994
29. Pussinen P, Jauhianinen M, Metso J, Tyynela J and Ehnholm C: Pig plasma phospholipid transfer protein facilitates HDL interconversion. J Lipid Res 36: 975-985, 1995.

30. Jauhianinen M, Metso J, Pahlman R, Blomqvist S, Vantal A and Ehnholm C: Human plasma phospholipid transfer protein causes high density lipoprotein conversion. J Biol Chem 268: 4032-4036, 1993.

31. Lusa S, Jauhianinen M, Metso J, Somerhariu P and Ehnholm C: The mechanism of human plasma phospholipid transfer proteininduced enlargement of high-density lipoprotein particles: evidence for particle fusion. Biochem J 313: 275-282, 1996

32. Eckardstein A, Jauhianinen M, Huang Y, et al: Phospholipid transfer protein mediated conversion of high density lipoproteins generates pre B1-HDL. Biochim Biophys Acta 1301: 255-262, 1996.

33. Barbaras R, Collet X, Chap H and Perret B: Specific binding of free apolipoprotein A-I to a high-affinity binding site on HepG2 cells: characterization of two high-density lipoprotein sites. Biochemistry 33: 2335-2340, 1994

34. Garcia A, Barbaras R, Collet X, Bogyo A, Chap H and Perret B High-density lipoprotein 3 receptor-dependent endocytosis pathway in human hepatoma cell line (HepG2). Biochemistry 35: 13064-13071, 1996.

35. Fackler OT and Grosse R: Cell motility through plasma membrane blebbing. J Cell Biol 181: 879-884, 2008.

36. Mellor HR and Harris AL: The role of the hypoxia-inducible BH3-only proteins BNIP3 and BNIP3L in cancer. Cancer Metastasis Rev 26: 553-566, 2007.

37. Willis SN, Fletcher JI, Kaufmann T, et al: Apoptosis initiated when BH3 ligands engage multiple Bcl-2 homologs, not Bax or Bak. Science 315: 856-859, 2007.

38. Lefranc F, Facchini V and Kiss R: Proautophagic drugs: a novel means to combat apoptosis-resistant cancers, with a special emphasis on glioblastomas. Oncologist 12: 1395-1403, 2007.

39. Okada $\mathrm{H}$ and Mak TW: Pathways of apoptotic and non-apoptotic death in tumour cells. Nat Rev Cancer 4: 592-603, 2004.

40. Lockshin RA and Zakeri Z: Apoptosis, autophagy, and more. Int J Biochem Cell Biol 36: 2405-2419, 2004.

41. Kondo Y, Kanzawa T, Sawaya R and Kondo S: The role of autophagy in cancer development and response to therapy. Nat Rev Cancer 5: 726-734, 2005.

42. Das P, Estephan R and Banerjee P: Apoptosis is associated with an inhibition of aminophospholipid translocase (APTL) in CNS-derived HN2-5 and HOG cells and phosphatidylserine is a recognition molecule in microglial uptake of the apoptotic HN2-5 cells. Life Sci 72: 2617-2627, 2003.

43. Mandal D, Mazumder A, Das P, Kundu M and Basu J: Fas-caspase 8- and caspase 3-dependent signalling regulates the activity of the aminophospholipid translocase and phosphatidylserine externalization in human erythrocytes. J Biol Chem 280: 39460-39467, 2005.

44. Frasch SC, Henson PM, Nagaosa K, Fessler MB and Bratton DL: Phospholipid flip-flop and phospholipid scramblase 1 (PLSCR 1) co-localize to uropod rafts in formylated Met-Leu-Phe-stimulated neutrophils. J Biol Chem 279: 17625-17633, 2004.

45. Wolfs H, Comfurius P, Rasmussen JT, Keuren JF, Lindhout T and Bevers EM: Activated scramblase and inhibited aminophospholipid translocase cause phosphatidylserine exposure in a distinct platelet fraction. Cell Mol Life Sci 62: 1514-1525, 2005.

46. Wang X, Wang J, Gengwo-Ando K, et al: C. elegans mitochondrial factor WAH-1 promotes phosphatidylserine externalization in apoptotic cells trough phospholipid scramblase SCRM-1. Nat Cell Biol 9: 541-549, 2007.

47. Papadopulos A, Vehring S, Lopez-Montero I, et al: Flippase activity detected with unlabeled lipids by shape changes of geant unilamellar vescicles. J Biol Chem 282: 15559-15568, 2007.

48. Van Blitterswijk WJ, Damen J, Hilkmann H and de Widt J: Alterations in biosynthesis and homeostatis of cholesterol and lipoprotein patterns in mice bearing a transplanted lymphoid tumor. Biochim Biophys Acta 816: 46-56, 1985.

49. Chekhun VF, Tryndiak VP, Todor IM, Mykhailenko VM, Kondrychyn IH and Kulyk HI: Phospholipid and cholesterol levels in the tumor cell plasma membranes with different sensitivity to doxorubicin. Ukr Biokhim Zh 75: 120-125, 2003. 